\title{
Effect of Arthrobacter Isolates on Germination, Chlorophyll Content, Nodulation, Yield and Nutrient Uptake by Soybean (Glycine max) in a Vertisol
}

\author{
Suman G. Sahu ${ }^{1 *}$, Ashok Kumar Rawat ${ }^{2}$, Ashish Kumar Dash ${ }^{1}$ and Narayan Panda ${ }^{1}$ \\ ${ }^{1}$ Department of Soil Science and Agricultural Chemistry, Odisha University of Agriculture \\ and Technology, Bhubaneswar-751003, India \\ ${ }^{2}$ Department of Soil Science and Agricultural Chemistry, Jawaharlal Nehru Krishi Vishwa \\ Vidyalaya, Jabalpur, M.P.-482004, India
}

*Corresponding author

\section{A B S T R A C T}

The present investigation was carried out with the objectives to evaluate the efficacy of thirteen short listed Arthrobacter isolates under field conditions with special reference to

\section{Keywords}

Soybean,

Germination,

Chlorophyll,

Nodulation, Yield,

Nutrient uptake

Article Info

Accepted:

15 September 2020

Available Online:

10 October 2020 germination, photosynthetic activity, yield, nodulation characters and nutrient uptake by soybean. Field evaluation was done during kharif 2015-16 at Research Field of Department of Soil Science and Agricultural Chemistry, JNKVV, Jabalpur, M.P. Outcome of the experimental findings revealed that most of the isolates showed their role for early seed germination at $4^{\text {th }}$ and $6^{\text {th }}$ days after sowing (DAS). A visual difference on early germination was noticed in the inoculated plots as compared to fertilizer un-inoculated isolates (FUI). Maximum chlorophyll content was recorded with isolate AR2 $(2.25 \mathrm{mg} / \mathrm{g}$ fresh leaf) which was $25 \%$ higher to FUI ( $1.80 \mathrm{mg} / \mathrm{g}$ fresh leaf). Maximum number of nodules (28/ plant) were formed by isolates AR2 and it was 33\% higher to FUI followed by AR4, AR9 and AR1 isolates. On considering the grain and straw yield after harvest it was observed that out of 13 Arthrobacter isolates only three were able to contribute significantly towards grain yield over FUI and these isolates were AR2, AR4, AR7. It was maximum $(1658 \mathrm{~kg} / \mathrm{ha}$ ) with isolate $\mathrm{AR} 2$. It was found that total $\mathrm{N}, \mathrm{P}$ and $\mathrm{K}$ uptake by crop was enhanced due to Arthrobacter seed inoculation but looking to significance of isolates over FUI, AR2 and AR7 significantly increased the total N, P and K uptake by crop over FUI. Average performance due to different isolates was 33, 27.9 and $24.8 \%$ more over FUI respectively. Looking to over all responses of thirteen isolates it was found that isolate AR2 performed best followed by AR4, AR7 and AR8.

\section{Introduction}

Soybean (Glycine max.) is known as the "GOLDEN BEAN" of the $20^{\text {th }}$ Century. It accounts for approximately $50 \%$ of total production of oil seed crops in the world. The name soya traces to the Chinese "CHIANGYIU”, meaning soy sauce and also known as 'miracle crop'. It has been cultivated since ancient times in countries like Brazil, United 
States, India and others. It was introduced to India centuries ago through the Himalayan Routes, and also brought in via Burma (now Myanmar) by traders form Indonesia.

Soybean is rapidly emerging as the most important oil seed crop in India. Soybean has great potential as an exceptionally nutritive and very rich protein food. It can supply the much needed protein to human diets, soybean contains $35-40 \%$ protein, $19 \%$ oil, $35 \%$ carbohydrate $(17 \%$ of which is a dietary fibre), 5\% minerals and several other components including vitamins (Liu, 1997). Owing to its amino acids composition, the protein of soybean is called a complete protein. In Madhya Pradesh the area under soybean cultivation during Kharif 2014 was 55.46 lakh ha with $1086 \mathrm{~kg} \mathrm{ha}^{-1}$ yield and 60.25 lakh MT production (SOPA, 2014).

Conn (1928) described a group of bacteria, extremely numerous in certain soils, which have a distinct characteristics, that they appeared as Gram-negative rods in young cultures and as Gram-positive cocci in older cultures. For these bacteria, Conn (1928) created the species Bacterium globiforme, which was later renamed as Arthrobacter globiformis, belonging to the genus Arthrobacter. These were originally described as being highly aerobic, nutritionally nonexacting and capable of liquefying gelatine slowly (Conn and Dimmick, 1947).

Soybean rhizosphere presented greater proportions of Bacillus, Pseudomonas and Arthrobacter genera, with Bacillus being prevalent in the non-rhizosphere soil and Pseudomonas in the rhizosphere (Cattelan et al., 1998). The maximum nitrogen-fixing activity was observed when wheat was inoculated with mixed cultures of diazotroph bacteria (Xanthomonas sp. + Arthrobacter sp.) (Biabani, 2012). In the rhizosphere a synergism between various bacterial genera such as Bacillus, Pseudomonas, Arthrobacter and Rhizobium has been shown to promote plant growth of various plants such as peanut, corn, soybean and maize (Dey et al., 2004).

Madhya Pradesh is a soybean state where soybean is grown since 1969 by practicing a conventional method of seed inoculation with Bradyrhizobia and application of recommended dose of fertilizers. Little literature is available that Arthrobacter plays a beneficial role towards crop production through PGPR effect and no much work has been done on this microorganism. Therefore, several isolation were made from different crop rhizospheres and these isolates were short listed under net house conditions.

The present investigation has been planned to evaluate the efficacy of short listed isolates under field conditions with special reference to germination, yield, chlorophyll content, nodulation characters and also their role uptake of nutrients by crop. By keeping in mind, the present investigation on "Effect of Arthrobacter isolates on germination, chlorophyll content, nodulation, yield and nutrient uptake by Soybean (Glycine max) in a Vertisol" was planned to evaluate the effectiveness of Arthrobacter isolates on soybean yield and other groeth associated properties.

\section{Materials and Methods}

The present investigation was conducted during kharif 2015-16 at the Research field of Jawaharlal Nehru Krishi Vishwa Vidyalaya, Jabalpur M.P. (India). The soil of the experimental site was Vertisol belonging to Montmorillonite, hypothermic family of Typic Haplusterts popularly known as "Black Cotton Soil". To determine the initial chemical properties of soil before layout of experiment, composite sample was prepared by randomly soil sampling $(0-15 \mathrm{~cm}$ depth) 
from different spot of the experimental field. Samples were, air-dried in the shade and then grounded by wooden roller, there after sieved through $2 \mathrm{~mm}$ mesh and stored in polyethylene bags. The soil samples thus obtained were subjected to various chemical analyses to assess the various chemical properties of soil.

Thirteen isolates of Arthrobacter were provided by Indian Institute of Soil Science, Bhopal, M.P. which were proved to be highly efficient in initial screenings under glass house conditions. These isolates were used for field studies on soybean crop. The isolates were AR1, AR2, AR3, AR4, AR5, AR6, AR7, AR8, AR9, AR10, AR11, AR12 and AR13. All these 13 isolates were selected for evaluation on growth and yield of soybean and also for the uptake of nutrients by crop. $40 \mathrm{gm}$ soybean seed was weighed separately for each plot in clean polythene bags. $1 \mathrm{ml}$ of liquid formulation of each isolate was transferred aseptically to previously sterilized tubes (micro centrifuge tubes). Sterilized gum acacia (2\%) was used as sticker solution and 1 $\mathrm{ml}$ of this solution was also transferred aseptically to micro centrifuge tubes separately. Seed treatment was done in shade and after it seeds were sown manually as early as possible. Nodulation studies were done at 45 days of sowing by uprooting 3 plants/plot very carefully taking sufficient care to avoid any losses or damage of nodules.

The rhizosphere soil was washed in the running water. After proper washing nodules of plants per plot were counted. After counting, the nodules were detached from the roots and were kept in small paper bags. Then the nodule fresh weight was taken. After that nodules were oven dried in hot air oven at $60^{\circ} \mathrm{C}$ for (18-20 hrs) 3-4 days (till constant weight) to record their oven dried weight. Plant samples were collected and oven dried for nutrient content estimation in both grain and straw.

\section{Results and Discussion}

Effect of Arthrobacter isolates on germination at $4^{\text {th }}$ and $6^{\text {th }}$ days after sowing (DAS) of the crop

Seed inoculation with different isolates of Arthrobacter along with recommended dose of fertilizer proved synergistic towards increasing the germination of seed at $4^{\text {th }}$ and $6^{\text {th }}$ days after sowing (Table 1).

Isolates AR2, AR4, AR6, AR8 and AR12 were able to increase seed germination at $4^{\text {th }}$ DAS significantly over FUI. Maximum germination was recorded with AR2 (42\%) and all the above stated isolates were statistically at par to it. Considering the average of all isolates it was $35 \%$ and it was higher to FUI by $25 \%$ while at $6^{\text {th }}$ DAS the highest germination of soybean seed was recorded with AR2 isolate (59\%) and it was the only significant treatment over FUI. Considering the average performance of Arthrobacter isolates it was $50 \%$ which was $10 \%$ more to FUI. This result may be due to production of indole acetic acid (IAA), ammonia $\left(\mathrm{NH}_{3}\right)$, hydrogen cyanide $(\mathrm{HCN})$, siderophore and catalase enzyme by PGPR like Alcaligens, Arthrobacter and Azospirillum is mainly responsible to increase germination, and other growth attributes of soybean (Joseph et al., 2007 and Yasmin et al., 2007). Arthrobacter had been reported to enhance germination and seedling vigour in tomato (Rathaur et al., 2012), maize (Shahsavani et al., 2009), rice (Mia et al., 2012) and soybean (Kumar et al., 2012). Rhizobacterial isolates that promote seed germination have been designated as emergence promoting rhizobacteria (Chanway, 1997). 
Table.1 Efficiency evaluation of Arthrobacter isolates on soybean seed germination at $4^{\text {th }}$ and $6^{\text {th }}$ days after sowing) DAS)

\begin{tabular}{|l|c|c|}
\hline Treatment (Different Isolates of & \multicolumn{2}{|c|}{ Germination (\%) of Soybean Crop } \\
\cline { 2 - 3 } Arthrobacter) & $\mathbf{4}^{\text {th }} \mathbf{D A S}$ & $\mathbf{6}^{\text {th }} \mathbf{D A S}$ \\
\hline AR1 & 31 & 53 \\
\hline AR2 & 42 & 59 \\
\hline AR3 & 35 & 52 \\
\hline AR4 & 37 & 47 \\
\hline AR5 & 33 & 50 \\
\hline AR6 & 37 & 47 \\
\hline AR7 & 31 & 50 \\
\hline AR8 & 38 & 49 \\
\hline AR9 & 32 & 51 \\
\hline AR10 & 33 & 46 \\
\hline AR11 & 36 & 47 \\
\hline AR12 & 39 & 48 \\
\hline AR13 & 35 & 49 \\
\hline FUI & 28 & 45 \\
\hline UFUI & 25 & 40 \\
\hline Sem \pm & 3.1 & 3.0 \\
\hline CD) P=0.05) & 8.8 & 8.4 \\
\hline CV) $\%)$ & 15.6 & 10.5 \\
\hline
\end{tabular}

FUI: Fertilized un-inoculated isolates; UFUI: Un-fertilized un-inoculated isolates

Table.2 Efficiency evaluation of Arthrobacter isolates on total chlorophyll content and biomass of soybean at 45 DAS

\begin{tabular}{|c|c|c|c|c|c|}
\hline \multirow{2}{*}{$\begin{array}{c}\text { Treatment } \\
\text { (Different Isolates } \\
\text { of Arthrobacter) }\end{array}$} & \multirow[t]{2}{*}{$\begin{array}{c}\text { chlorophyll content } \\
\text { (mg/g fresh leaf) }\end{array}$} & \multicolumn{2}{|c|}{$\begin{array}{l}\text { Fresh biomass } \\
\text { (g/plant) }\end{array}$} & \multicolumn{2}{|c|}{$\begin{array}{c}\text { Oven dried biomass } \\
\text { (g/plant })\end{array}$} \\
\hline & & Shoot & Root & Shoot & Root \\
\hline AR1 & 2.06 & 8.34 & 1.45 & 2.64 & 0.53 \\
\hline AR2 & 2.25 & 10.27 & 1.73 & 2.91 & 0.63 \\
\hline AR3 & 1.99 & 8.71 & 1.35 & 2.57 & 0.45 \\
\hline AR4 & 2.05 & 9.92 & 1.51 & 2.40 & 0.52 \\
\hline AR5 & 1.93 & 9.85 & 1.58 & 2.48 & 0.59 \\
\hline AR6 & 2.04 & 9.75 & 1.37 & 2.59 & 0.52 \\
\hline AR7 & 1.95 & 9.76 & 1.58 & 2.55 & 0.55 \\
\hline AR8 & 1.85 & 9.70 & 1.52 & 2.61 & 0.48 \\
\hline AR9 & 2.02 & 9.11 & 1.70 & 2.69 & 0.55 \\
\hline AR10 & 1.84 & 7.77 & 1.60 & 2.58 & 0.53 \\
\hline AR11 & 2.14 & 9.50 & 1.64 & 2.26 & 0.59 \\
\hline AR12 & 2.19 & 8.91 & 1.38 & 2.66 & 0.52 \\
\hline AR13 & 2.17 & 8.77 & 1.50 & 2.50 & 0.52 \\
\hline FUI & 1.80 & 8.64 & 1.26 & 2.22 & 0.54 \\
\hline UFUI & 1.38 & 6.64 & 1.10 & 1.71 & 0.46 \\
\hline Sem \pm & 0.13 & 0.81 & 0.14 & 0.22 & 0.05 \\
\hline $\mathrm{CD}(\mathrm{P}=0.05)$ & 0.39 & 2.32 & 0.39 & 0.64 & 0.14 \\
\hline CV $(\%)$ & 11.81 & 15.57 & 15.98 & 15.62 & 16.12 \\
\hline
\end{tabular}

FUI: Fertilized un-inoculated isolates; UFUI: Un-fertilized un-inoculated isolates 
Table.3 Efficiency evaluation of Arthrobacter isolates on soybean nodulation and $\mathrm{N}$ content $(\%)$ at 45 DAS

\begin{tabular}{|l|c|c|c|c|}
\hline $\begin{array}{c}\text { Treatment } \\
\text { (Different } \\
\text { Isolates of } \\
\text { Arthrobacter) }\end{array}$ & $\begin{array}{c}\text { No.of nodules } \\
\text { /plant }\end{array}$ & $\begin{array}{c}\text { Nodulation } \\
\text { nodules (g/plant) }\end{array}$ & $\begin{array}{c}\text { N content } \\
\text { (\%) }\end{array}$ \\
\hline AR1 & 23 & 0.55 & 0.20 & \\
\hline AR2 & 28 & 0.63 & 0.22 & 3.25 \\
\hline AR3 & 20 & 0.57 & 0.17 & 3.69 \\
\hline AR4 & 25 & 0.54 & 0.18 & 3.53 \\
\hline AR5 & 19 & 0.52 & 0.21 & 3.43 \\
\hline AR6 & 22 & 0.52 & 0.19 & 3.21 \\
\hline AR7 & 21 & 0.52 & 0.21 & 3.47 \\
\hline AR8 & 21 & 0.62 & 0.21 & 3.55 \\
\hline AR9 & 24 & 0.59 & 0.22 & 3.21 \\
\hline AR10 & 22 & 0.56 & 0.20 & 3.24 \\
\hline AR11 & 19 & 0.57 & 0.19 & 3.51 \\
\hline AR12 & 22 & 0.62 & 0.21 & 3.32 \\
\hline AR13 & 22 & 0.53 & 0.17 & 3.27 \\
\hline FUI & 21 & 0.51 & 0.17 & 3.15 \\
\hline UFUI & 17 & 0.43 & 0.14 & 2.89 \\
\hline Sem \pm & 2.1 & 0.05 & 0.02 & 0.18 \\
\hline CD (P=0.05) & 6.2 & 0.13 & 0.06 & 0.51 \\
\hline CV $(\%)$ & 17.1 & 14.80 & 18.8 & 9.20 \\
\hline
\end{tabular}

FUI: Fertilized un-inoculated isolates; UFUI: Un-fertilized un-inoculated isolates

Table.4 Efficiency evaluation of Arthrobacter isolates on grain yield and

NPK uptake by grain of Soybean

\begin{tabular}{|l|c|c|c|c|}
\hline \multirow{2}{*}{$\begin{array}{c}\text { Treatment (Different } \\
\text { Isolates of Arthrobacter) }\end{array}$} & $\begin{array}{c}\text { Grain Yield } \\
\text { (kg/ha) }\end{array}$ & \multicolumn{3}{|c|}{ Nutrient Uptake by Grain (kg/ha) } \\
\hline AR1 & 1420 & $\mathbf{N}$ & $\mathbf{P}$ & $\mathbf{K}$ \\
\hline AR2 & 1658 & 17.23 & 4.95 & 23.2 \\
\hline AR3 & 1425 & 80.66 & 6.66 & 26.5 \\
\hline AR4 & 1644 & 100.21 & 4.94 & 25.9 \\
\hline AR5 & 1459 & 86.44 & 5.69 & 27.0 \\
\hline AR6 & 1301 & 78.62 & 4.90 & 24.3 \\
\hline AR7 & 1618 & 96.07 & 6.33 & 18.6 \\
\hline AR8 & 1475 & 84.70 & 5.66 & 28.4 \\
\hline AR9 & 1440 & 82.52 & 5.08 & 23.3 \\
\hline AR10 & 1410 & 83.55 & 5.09 & 22.2 \\
\hline AR11 & 1391 & 82.11 & 4.91 & 21.0 \\
\hline AR12 & 1380 & 81.00 & 5.18 & 22.2 \\
\hline AR13 & 1377 & 80.22 & 5.25 & 24.0 \\
\hline FUI & 1301 & 71.35 & 4.55 & 20.0 \\
\hline UFUI & 1012 & 52.17 & 2.90 & 14.1 \\
\hline Sem \pm & 82.66 & 5.7 & 0.47 & 2.66 \\
\hline CD(P=0.05) & 236.25 & 16.3 & 1.35 & 7.60 \\
\hline CV $(\%)$ & 10.08 & 12.0 & 15.66 & 19.94 \\
\hline
\end{tabular}

FUI: Fertilized un-inoculated isolates; UFUI: Un-fertilized un-inoculated isolates 
Table.5 Efficiency evaluation of Arthrobacter isolates on straw yield and NPK uptake by straw of Soybean

\begin{tabular}{|c|c|c|c|c|}
\hline \multirow{2}{*}{$\begin{array}{c}\text { Treatment } \\
\text { (Different Isolates of } \\
\text { Arthrobacter) }\end{array}$} & \multirow[t]{2}{*}{ Straw Yield (kg/ha) } & \multicolumn{3}{|c|}{ Nutrient Uptake by straw (kg/ha) } \\
\hline & & $\mathbf{N}$ & $\mathbf{P}$ & $\mathbf{K}$ \\
\hline AR1 & 5802 & 138.99 & 8.3 & 78.7 \\
\hline AR2 & 6842 & 183.38 & 12.1 & 115.9 \\
\hline AR3 & 5978 & 116.28 & 7.0 & 77.6 \\
\hline AR4 & 6298 & 167.09 & 10.2 & 99.9 \\
\hline AR5 & 6076 & 113.87 & 7.8 & 97.4 \\
\hline AR6 & 6366 & 139.12 & 9.9 & 86.3 \\
\hline AR7 & 6215 & 127.36 & 10.8 & 93.5 \\
\hline AR8 & 6143 & 141.15 & 8.6 & 77.0 \\
\hline AR9 & 6032 & 126.68 & 7.7 & 57.2 \\
\hline AR10 & 5701 & 124.14 & 7.2 & 90.6 \\
\hline AR11 & 5602 & 110.55 & 8.1 & 68.8 \\
\hline AR12 & 5285 & 116.58 & 7.0 & 81.4 \\
\hline AR13 & 5234 & 134.22 & 7.7 & 73.9 \\
\hline FUI & 5211 & 93.84 & 6.6 & 67.2 \\
\hline UFUI & 3787 & 55.10 & 4.1 & 33.2 \\
\hline $\operatorname{Sem} \pm$ & 592.57 & 17.0 & 1.27 & 10.19 \\
\hline $\mathrm{CD}(\mathrm{P}=\mathbf{0 . 0 5})$ & 1693.63 & 48.5 & 3.62 & 29.12 \\
\hline $\mathrm{CV}(\%)$ & 17.78 & 23.3 & 26.67 & 22.08 \\
\hline
\end{tabular}

FUI: Fertilized un-inoculated isolates; UFUI: Un-fertilized un-inoculated isolates

Table.6 Efficiency evaluation of Arthrobacter isolates on total uptake of nutrients

(NPK) by crop Soybean

\begin{tabular}{|l|c|c|c|}
\hline \multirow{2}{*}{ Treatment (Different } & \multicolumn{3}{|c|}{ Total NPK Uptake by Crop Soybean $\mathbf{( K g / h a )}$} \\
\hline Asolates of Arthrobacter) & N & P & K \\
\hline AR1 & 216 & 13 & 102 \\
\hline AR2 & 286 & 19 & 142 \\
\hline AR3 & 196 & 12 & 104 \\
\hline AR4 & 267 & 17 & 127 \\
\hline AR5 & 200 & 13 & 122 \\
\hline AR6 & 218 & 15 & 105 \\
\hline AR7 & 223 & 17 & 122 \\
\hline AR8 & 226 & 14 & 102 \\
\hline AR9 & 209 & 13 & 81 \\
\hline AR10 & 208 & 12 & 113 \\
\hline AR11 & 193 & 13 & 90 \\
\hline AR12 & 198 & 12 & 104 \\
\hline AR13 & 214 & 13 & 98 \\
\hline FUI & 165 & 11 & 87 \\
\hline UFUI & 107 & 7 & 47 \\
\hline Sem \pm & 16.0 & 1.34 & 10.25 \\
\hline CD (P=0.05) & 45.6 & 3.84 & 29.28 \\
\hline CV $(\%)$ & 13.3 & 17.34 & 17.23 \\
\hline FUI & & & \\
\hline
\end{tabular}

FUI: Fertilized un-inoculated isolates; UFUI: Un-fertilized un-inoculated isolates 
Effect of Arthrobacter isolates on total chlorophyll content and biomass of soybean

At 45 DAS chlorophyll content in soybean leaves was determined and it was found that only two isolates (AR2 and AR12) were able to increase chlorophyll content significantly over FUI (Table 2). Maximum chlorophyll content $\left(\right.$ 'a' $+{ }^{\circ} \mathrm{b}$ ') was recorded with isolate AR2 $(2.25 \mathrm{mg} / \mathrm{g}$ fresh leaf) which was $25 \%$ higher to FUI $(1.80 \mathrm{mg} / \mathrm{g}$ fresh leaf). On considering the overall performance of Arthrobacter isolates the chlorophyll content was $2.03 \mathrm{mg} / \mathrm{g}$ fresh leaf which was $2.7 \%$ higher to FUI. It seems involvement Arthrobacter isolates accelerates the iron uptake in plant cell which helps in nucleic acids metabolism in chloroplast (Sharma et al., 2016) that resulted in better chlorophyll content.

Looking up to the fresh weight of plants at 45 DAS (Table 2) it was seen that all isolates could increase the shoot fresh weight numerically non significantly over FUI. Isolates AR2 maintained its superiority by yielding maximum fresh weight of shoot. With regard to shoot oven dry weight only AR2 isolate was significantly better over FUI. However, other isolates could increase it numerically over FUI. Isolate AR2 maintained its significant superiority for root fresh biomass over FUI but for oven dry weight it was not significant but was maximum among all the isolates. It is apperent from the data that all isolates reflected better performance over FUI although it was statistically non significant. Dell'Amico et al., (2005) revealed that the phytohormone IAA production offers great promise for sustaining the increased crop productivity by increasing the plant biomass. Similar results were found by Arruda et al., 2013 and Upadhyaya et al., 2012. Use of Arthrobacter isolates enhance root development either directly by producing phytohormones or indirectly by inhabiting pathogens through the synthesis of different compounds (Benizri et al., 2001).

\section{Effect of Arthrobacter isolates on Nodulation and $\mathrm{N}$ content of nodules}

Nodulation studies were carried out at 45 DAS i.e. maximum vegetative growth stage where no. of nodules, their fresh and oven dry weight were recorded and nitrogen content was estimated (Table 3). When no. of nodules was considered, it was found that most of the isolates were not able to increase it over FUI except AR2. Maximum number of nodules (28/ plant) were yielded by isolates AR2 and it was 33\% higher to FUI followed by AR4, AR9 and AR1 isolates.

On considering fresh weight and dry weight of nodules, none of the isolates were found statistical superiority over FUI but isolate AR2 remained on top by scoring highest fresh weight of nodules among all of the isolates. On taking into consideration the average performance of isolates toward nodulation it was found that no of nodules was $5.4 \%$ more and their oven dried weight was $10 \%$ more to FUI which clearly indicates the impact of seed inoculation with Arthrobacter isolates.

Lowest nitrogen content in nodules was found with FUI $(3.15 \%)$ while it was highest and statistically significant with isolate AR2 (3.69\%) followed by AR8 (3.55\%). Out of 13 inoculants treatments (which comprised of different isolates) all are at par with AR2. Most PGPRs belong to the genera Arthrobacter, Bacillus, Micromonospora, Pseudomonas and Streptomycetes stimulates nodulation in legumes which may be due to the production of phytohormones such as auxin, gibberellins and cytokinins possibly a mechanism used by PGPR to enhance nodule formation. Available reports indicate 
improved yield of legumes and nodulation when co-inoculated with PGPB compared to inoculation with Rhizobium alone (Egamberdieva et al., 2010 and Yadegari et al., 2010).

\section{Effect of Arthrobacter isolates on Grain yield and nutrient uptake (NPK) by Soybean}

On considering the grain yield (Table 4) after harvest it was observed that out of 13 Arthrobacter isolates only three were able to contribute significantly towards grain yield over FUI and these isolates were AR2, AR4, AR7. It was maximum (1658 kg/ha) with isolate no.AR2. When statistical resemblance of AR2 was worked out, it was found that most of the isolates were in resemblance to it except AR1, AR6, AR10, AR11, AR12 and AR13. On working the average performance of all the 13 isolates the grain yield was $1461 \mathrm{~kg} / \mathrm{ha}$ which was $12 \%$ more to FUI(1301kg/ha).

With regard to $\mathrm{N}, \mathrm{P}$ and $\mathrm{K}$ uptake by grain it was found that isolates AR2, AR4 and AR7 gave statistically higher $\mathrm{N}$ and $\mathrm{P}$ uptake over FUI while potassium uptake was significant due to AR7 only. Considering the average performance of Arthrobacter isolates it was $20.2 \%, 19.7 \%$ and $20 \%$ higher over FUI.

\section{Effect of Arthrobacter isolates on straw} yield and nutrient uptake (NPK) by Soybean

Straw yield was found non significant (Table 5) due to isolates over FUI but the average performance of isolates $(5967 \mathrm{~kg} / \mathrm{ha})$ was $14.5 \%$ higher over FUI (5211 kg/ha). All the Arthrobacter isolates increased NPK uptake numerically over FUI. AR2 isolate maintained its superiority by the maximum NPK uptake by straw along with isolate AR4 and these two isolates commonly increased the N, P and K uptake by straw over FUI. On considering the average performance of all isolates towards total $\mathrm{N}, \mathrm{P}$ and $\mathrm{K}$ uptake by straw it was $42.6 \%, 31.0 \%$ and $25.7 \%$ respectively more over FUI.

Phytohormone IAA production offers great promise for sustaining the increased crop productivity by increasing plant biomass (Dell'Amico et al., 2005). Similar result on grain yield of barley was also observed by Belimov et al., (1995). These rhizosphere bacteria enhance growth of plant and yield by nitrogen fixation, solubilization of phosphorus, production of phytohormones such as auxins (indole acetic acid (IAA)), cytokinins and gibberellins, sequestering of iron by production of siderophores, lowering of ethylene concentration (Kumar et al., 2014). Combined inoculation consistently enhanced growth and yield of crop to a level equal to or greater than that achieved by single inoculation, and far greater than that of the uninoculated control plants. This might be due to the colonizing the hair, cortical cells and enhanced root surface area and consequently more acquisition of nutrients as well as plant hormones

\section{Total nutrients (NPK) uptake by crop Soybean}

On perusal of data (Table 6), it was found that total N, P and K uptake by crop was enhanced due to Arthrobacter seed inoculation but looking to significance of isolates over FUI no definite trend could be observed except that isolates AR2 and AR7 significantly increased the total N, P and $\mathrm{K}$ uptake by crop over FUI. Isolate AR2 was found the best towards total NPK uptake. Average performance due to different isolates was 33, 27.9 and $24.8 \%$ more over FUI respectively. PGPR promote the growth of the plant and increase the root surface area or the general root architecture. Plants growing better in turn 
release higher amounts of $\mathrm{C}$ in root exudates. The release of more $\mathrm{C}$ prompts increase in microbial activity, and this process continues in a cycle and thus yield and nutrient uptake by crop is enhanced.

In conclusion from the present field evaluation conducted during kharif 2015-16 at Research Field of Department of Soil Science and Agricultural Chemistry, JNKVV, Jabalpur, M.P was concluded that most of the isolates showed their role for early seed germination at $4^{\text {th }}$ and $6^{\text {th }}$ days after sowing (DAS). A visual difference on early germination was noticed in the inoculated plots as compared to fertilizer un-inoculated isolates (FUI). Maximum chlorophyll content was recorded with isolate AR2 $(2.25 \mathrm{mg} / \mathrm{g}$ fresh leaf) which was $25 \%$ higher to FUI $(1.80 \mathrm{mg} / \mathrm{g}$ fresh leaf). Maximum number of nodules (28/ plant) were formed by isolates AR2 and it was 33\% higher to FUI followed by AR4, AR9 and AR1 isolates. Yield was maximum $(1658 \mathrm{~kg} / \mathrm{ha})$ with isolate AR2. It was found that total $\mathrm{N}, \mathrm{P}$ and $\mathrm{K}$ uptake by crop was enhanced due to Arthrobacter seed inoculation but looking to significance of isolates over FUI, AR2 and AR7 significantly increased the total N, P and K uptake by crop over FUI. Looking to over all responses of thirteen isolates it was found that isolate AR2 performed best followed by AR4, AR7 and AR8.

\section{References}

Arruda L, Beneduzi A, Martins A, Lisboa, B, Lopes C, Bertolo $\mathrm{F}$ and Vargas LK. 2013. Screening of rhizobacteria isolated from maize) Zea mays L.) in Rio Grande do Sul State) South Brazil) and analysis of their potential to improve plant growth. Applied Soil Ecology, 63: 15-22.

Belimov AA, Kojemiakov AP, Chuvarliyeva CV. 1995. Interaction between barley and mixed cultures of nitrogen fixing and phosphate-solubilizing bacteria. Plant Soil., 173: 29-37.

Benizri E, Baudoin E and Guckert A. 2001. Root colonization by inoculated plant growth promoting rhizobacteria. Biocontrol Science and Technology, 11 (5): 557-574.

Biabani A. 2012. Formation of artificial Nitrogen-fixing bacteria symbioses with wheat. Journal of Applied Biosciences 6) 2): $169-172$.

Cattelan AJ, Hartel PG and Fuhrmann JJ. 1998. Bacterial composition in the rhizosphere of nodulating and nonnodulating soybean. Soil Sci. Soc. Am. J., 62: 1549-1555.

Chanway CP. 1997. Inoculation of tree roots with PGPR soil bacteria: an emerging technology for reforestation. Forest Science, 43) 1): 99-112.

Conn HJ and Dimmick I. 1947. Soil bacteria similar in morphology to Mycobacterium and Corynebacterium. Journal of Bacteriology, 54(3): 291.

Conn HJ. 1928. A type of bacteria abundant in productive soils, but apparently lacking in certain soils of low productivity. New York State Agricultural Experimental Station Technical Bulletin No. 138: 3-26.

Dell'Amico E, Cavalca L and Andreoni V. 2005. Analysis of rhizobacterial communities in perennial Graminaceae from polluted water meadow soil, and screening of metal-resistant, potentially plant growth-promoting bacteria. FEMS Microbiol. Ecol. 52: 153-162.

Dey R, Pal KK, Bhatt DM and Chauhan SM. 2004. Growth promotion and yield enhancement of peanut) Arachis hypogaea L.) by application of plant growth-promoting rhizobacteria. Microbial. Res. 159) 4): 371-394.

Egamberdieva, D., Berg, G., Lindstrom, K. and Rasanen, L.A. 2010 Co-inoculation of Pseudomonas spp. with Rhizobium 
improves growth and symbiotic performance of fodder galega) Galega orientalis Lam.). European Journal of Soil Biology, 46: 269-272.

Joseph B, Patra RR and Lawrence R. 2007. Characterization of plant growth promoting Rhizobacteria associated with chickpea) Cicer arietinum L). International J. Plant Production 1: 141152.

Kumar A, Kumar A, Devi S, Patil S, Payal C and Sushila Negi S. 2012. Isolation, screening and characterization of bacteria from rhizospheric soils for different plant growth promotion) PGP) activities: an in vitro study. Rec. Res. Sci. Tech. 4: 1-5.

Kumar A, Maurya BR, and Raghuwanshi R. 2014. Isolation and characterization of PGPR and their effect on growth, yield and nutrient content in wheat) Triticum aestivum L.). Biocatalysis and Agricultural Biotechnology, 3) 4): 121128.

Liu K. 1997. Chemistry and nutritional value of soybean components. Soybeans pp, 25-113 Springer, Boston, MA. https://doi.org/10.1007/978-1-46151763-4_2

Mia MA, Shamsuddin ZH and Mahmood M. 2012. Effects of rhizobia and plant growth promoting bacteria inoculation on germination and seedling vigor of lowland rice. Afr. J. Biotechnol. 11; 3758-3765.

Rathaur P, Raja W, Ramteke PW and John
SA. 2012. Effect of UV-B tolerant plant growth promoting rhizobacteria) PGPR) on seed germination and growth of Withania somnifera. Adv. Appl. Sci. Res. 3: 1399-1404.

Shahsavani S, Gholami A and Nezarat S. 2009. The effect of plant growth promoting rhizobacteria) PGPR) on germination, seedling growth and yield of maize. World Academy of Science, Engineering and Technology 49: 55-60.

Sharma M, Mishra V, Rau N and Sharma RS. 2016. Increased iron stress resilience of maize through inoculation of siderophore producing Arthrobacter globiformis from mine. Journal of Basic Microbiology 56) 7): 719-735

SOPA 2014. The Soybean Processors Association of India. www.sopa.org.

Upadhyay SK, Singh JS, Saxena AK and Singh DP. 2012. Impact of PGPR inoculation on growth and antioxidant status of wheat under saline conditions. Plant Biology 14: 605-611

Yadegari, M., Rahmani, H.A., Noormohammadi, G. and Ayneband, A. 2010 Plant growth promoting rhizobacteria increase growth, yield and nitrogen fixation in Phaseolus vulgaris. Journal of Plant nutrition, 33) 12): 1733-1743.

Yasmin F, Othman R, Sijam K and Saad MS. 2007. Effect of PGPR inoculation on growth and yield of sweet potato. J. Biol. Sci., 7) 2): 421-424.

\section{How to cite this article:}

Suman G. Sahu, Ashok Kumar Rawat, Ashish Kumar Dash and Narayan Panda. 2020. Effect of Arthrobacter Isolates on Germination, Chlorophyll Content, Nodulation, Yield and Nutrient Uptake by Soybean (Glycine max) in a Vertisol. Int.J.Curr.Microbiol.App.Sci. 9) 10): 18581867. doi: https://doi.org/10.20546/ijcmas.2020.910.227 